Seção Livre 



\title{
"Não adianta insultar os patrões": sindicatos, nacionalismo e 0 ambiente de trabalho em Gana, 1950-1987
}

\author{
Dmitri van den Bersselaar*
}

Resumo: As lutas pelo controle do local de trabalho não envolvem apenas a força de trabalho e a administração, pois são frequentemente influenciadas por questões políticas mais amplas e pela intervenção direta do Estado. Este trabalho explora a complexa interação entre trabalhadores, força de trabalho organizada, administração, política e governo em Gana durante os períodos colonial e póscolonial, entre 1948 e 1987, tomando a Unilever, subsidiária da UAC, como caso de estudo. E delineia como, a partir da década de 1950 até o início dos anos de 1980, o controle do Estado sobre as relações de trabalho reduziu o espaço de negociação entre os sindicatos e a gestão da empresa em Gana. Esse sistema foi rapidamente desmantelado depois de 1982, primeiro por um governo revolucionário que incentivou a participação direta dos trabalhadores em detrimento do trabalho organizado, depois pelas reformas neoliberais de livre mercado. Essas últimas reformas restabeleceram o "direito da administração à gestão". No entanto, após décadas de oportunidades limitadas para negociar, a administração da empresa não tinha experiência nem as habilidades necessárias para exercer uma efetiva liderança, e a força de trabalho organizada havia sido desestabilizada.

Palavras-chave: Gana; descolonização; sindicatos; controle sobre o local de trabalho; companhias multinacionais; reformas neoliberais.

Abstract: Struggles over control over the workplace do not only involve labour
and management, as they are frequently influenced by broader political issues and
direct state intervention. This paper explores the complex interaction between
workers, organised labour, management, politics and government for Ghana
during the colonial and postcolonial decolonisation years between 1948 and 1987 ,
taking Unilever-subsidiary UAC as a case study. It traces how from the 1950 s until
the early 1980s, state control of labour relations reduced the negotiating space
for trade unions and company management in Ghana. This system was rapidly
dismantled after 1982, first by a revolutionary government which encouraged
direct worker participation at the expense of organised labour, then by neo-liberal
* Doutor em Ciências Sociais pela Leiden University (Holanda). Professor da Universität Leipzig (Alemanha). 
free market reforms. The latter reforms restored 'management's right to manage'. However, after decades of limited opportunities to negotiate, existing corporate management did not have the experience or skills to provide effective leadership, while the position of organised labour had been undermined.

Keywords: Ghana; decolonisation; trade unions; workplace control, multinational companies; neo-liberal reforms.

\section{Contextualizando: trabalhadores da United Africa Company - UAC, e a Greve Geral de 1950}

Nas décadas que se seguiram à II Guerra Mundial, os sindicatos em muitas colônias africanas tiveram que decidir se iriam comprometer-se com as demandas dos políticos nacionalistas pela independência, assumindo um papel de liderança nas lutas contra o colonialismo, ou se iriam limitar-se às negociações com o patronato sobre as condições dos trabalhadores. No caso de Gana (então ainda denominado Costa do Ouro), essa questão surgiu em janeiro de 1950, quando o Gold Coast Trades Union Congress - TUC (Confederação de Sindicatos da Costa do Ouro) convocou uma greve geral em apoio à União dos Trabalhadores dos Serviços Meteorológicos na sua disputa contra o governo. Desde então, essa greve entrou para os livros de história como a "Ação Positiva" de Kwame Nkrumah: uma campanha de desobediência civil para forçar o governo colonial a aceitar as exigências dos nacionalistas. ${ }^{1}$ A greve foi direcionada contra o governo, mas também envolvia empregados de empresas comerciais, como a United Africa Company (conhecida por suas iniciais UAC).

Muitos empregados da UAC não aderiram à greve. Na verdade, a União dos Trabalhadores da UAC não os incentivou a participar, já que não havia conflito com o empregador. ${ }^{2}$ A diretoria, no entanto, resolveu interpretar a decisão de um funcionário de aderir ou não à greve como uma indicação de sua lealdade para com a empresa. Após a paralisação, foi solicitado aos administradores regionais que enviassem listas à sede com nomes de quem havia demonstrado uma "lealdade exemplar por comparecimento integral". ${ }^{3}$ Interpretou-se o comportamento dos funcionários durante a greve também em termos de maturidade: o diretor geral da UAC na Costa do Ouro destacou o modo como "os mais velhos contiveram a impetuosidade dos mais jovens" durante a paralisação. ${ }^{4} \mathrm{~A}$ empresa adotou uma linha dura contra os grevistas, demitindo e impedindo que fossem recontratados os que haviam abandonado seus postos de trabalho durante a greve. ${ }^{5} \mathrm{~A}$ UAC estava politicamente vulnerável no período da descolonização por ser uma das maiores organizações do país, dominando setores inteiros da economia, e por suas

2 JEFFRIES, Richard. Class, Power and Ideology in Ghana: the Railwaymen of Sekondi. Cambridge: Cambridge University Press, 1978, p. 58.

3 Unilever Archives \& Records Management (UARM), United Africa Company Collection (UAC), UAC/2/20/3/1 UAC of Ghana Limited: General Manager's Private Files (Arquivos Privados do Diretor Geral).

4 "Watches for long service - impressive ceremony at Accra". Gold Coast UAC News 1.6 (1950), front page.

5 DECKER, Stephanie "Building up Goodwill: British Business, Development and Economic Nationalism in Ghana and Nigeria, 1945-1977" (Tese de doutorado em História, University of Liverpool, 2006), p. 218. 
estreitas relações com a administração colonial. ${ }^{6}$ Menos de dois anos antes, suas instalações haviam sido um dos principais alvos de ataques e pilhagens durante as revoltas de 1948 em Acra, que haviam irrompido no contexto de um protesto nacionalista contra a dominação da economia por empresas estrangeiras.

A administração da UAC preocupou-se, com razão, que a greve de 1950 levasse a empresa de volta aos conflitos nacionalistas. Escolher uma interpretação da greve que frisasse a lealdade e a maturidade dos funcionários fazia parte de um firme propósito de evitar que se politizasse o ambiente de trabalho. Por sua parte, o movimento nacionalista pressionou os trabalhadores da UAC para que fizessem justamente isso. Os que não haviam aderido à greve sofreram intimidações. Um administrador de Sekondi relatou que foram afixados por toda a cidade como "lacaios" os nomes dos empregados que continuavam a comparecer ao trabalho, e que esses indivíduos tiveram até que receber proteção policial.? Informou também que as casas desses trabalhadores foram atingidas por explosivos. No contexto do nacionalismo e da emergência do Estado pós-colonial, o ambiente de trabalho da UAC estava se tornando cada vez mais politizado, apesar dos esforços da administração e da União dos Trabalhadores dessa empresa para impedir que isso acontecesse. Pode até ser uma observação óbvia, porém é importante enfatizar que os esforços para controlar o ambiente de trabalho não implicavam unicamente nas questões trabalhistas e na administração, mas também nas questões políticas mais amplas e a intervenção direta do Estado influenciaram profundamente esse intento. ${ }^{8}$ Em Gana, a organização trabalhista não foi afetada apenas pelas políticas anticoloniais: sua exposição à política geral tornou-se bem traumática da metade para o final da década de 1950, igualmente no final dos anos 1960, durante os anos 70 e, novamente, no início dos anos 80.

\section{A questão: a luta pelo controle do ambiente de trabalho}

Tem sido observado com frequência em países africanos antes colonizados por poderes europeus, que o desenvolvimento do movimento sindical foi complicado pelo processo de descolonização e pelo papel que os sindicatos assumiram nesse processo, assim como pela subsequente intervenção dos governos africanos independentes. De fato, as conexões entre os movimentos sindicais da África colonial e os movimentos pela independência política têm sido objeto de estudo desde a obra de Thomas Hodgkin Nationalism in Colonial Africa, de 1956, que prestou considerável atenção aos sindicatos, refletindo a "importância intrínseca dos sindicatos na história de quase todos os nacionalismos modernos". 9 Os sindicatos assumiram um papel estrategicamente eficaz no esfacelamento do Estado colonial, apesar do pequeno número de sindicalizados e do limitado grau de industrialização das economias da África colonial..$^{10}$ Contudo, conforme observou Frederick Cooper: "Se, em determinadas circunstâncias, as reivindicações dos

6 FIELDHOUSE, David K. Merchant Capital and Economic Decolonization: The United Africa Company 1929-1987. Oxford: Clarendon Press, 1994, p. 338-49.

7 UARM UAC/2/20/3/2 Carta de K. R. Adams, District Manager, Sekondi, para P. H. Fitz-Gerald, General Manager, The United Africa Company Limited, 2 fev. 1950.

8 CRISP, Jeff. The Story of an African Working Class. Ghanaian Miners' Struggles 1870-1980. Londres: Zed Books, 1984, p. 1-10.

9 HODGKIN, Thomas. Nationalism in Colonial Africa. Londres: Frederick Muller, 1956, p. 117.

10 FREUND, Bill. The African Worker. Cambridge: Cambridge University Press, 1988, p. 91. 
sindicatos contra os capitalistas estrangeiros e o Estado colonial facilitaram outros ataques contra o Estado colonial - e se, por vezes, sindicatos e partidos foram grandes aliados - em outras, os dois movimentos se opuseram". ${ }^{11}$ Hoje existe uma extensa literatura sobre o envolvimento dos sindicatos na política nacionalista e sobre as políticas posteriores direcionadas a organizações trabalhistas dos estados africanos independentes, o que demonstra que, na maioria dos casos, o Estado pós-colonial tentou estabelecer um controle sobre o movimento sindical. ${ }^{12}$ Outros estudos têm analisado o impacto do envolvimento em greves e na organização sindical sobre as identidades de gênero, de classe e individuais. ${ }^{13}$ Há também estudos sobre as respostas das gestões das empresas estrangeiras às organizações trabalhistas e às políticas nacionalistas. ${ }^{14}$

Este artigo lança uma luz a mais sobre essas questões ao destacar o impacto no ambiente de trabalho: até que ponto os sindicatos e as políticas nacionalistas politizaram o ambiente de trabalho? Que impacto teve isso nas subsequentes disputas trabalhistas dentro da empresa? Como essa questão influenciou a luta pelo controle do ambiente de trabalho? Durante as primeiras décadas póscoloniais, o Estado de Gana logrou atrair o movimento sindical para a sua órbita, usando-o, além de tudo, para garantir apoio ao partido dominante, a Convention People's Party (CPP), e ao governo. Por sua vez, contudo, o governo não esteve particularmente do lado dos trabalhadores. Manteve os salários em níveis baixos e incentivou o patronato nos seus objetivos de aumento da produtividade. Porém, nem os trabalhadores nem as empresas puderam contar com o apoio do governo em caso de uma greve. Ao contrário, durante o declínio da economia ganense, entre 1962 e 1983, trabalhadores, sindicatos, patronato e o Estado, todos se esforçaram para dominar o ambiente de trabalho. Em 1982, a UAC perdeu o controle de uma de suas fábricas após um levante dos trabalhadores, que recebeu apoio do governo ganense. A fábrica permaneceria nas mãos dos trabalhadores por cinco anos, após o que o governo convidou a UAC a reassumir o controle administrativo, contrariando o desejo dos funcionários. ${ }^{15}$

O restante deste artigo explora esses aspectos em ordem (grosso modo) cronológica. Em primeiro lugar, serão discutidas as especificidades do ambiente de trabalho da UAC nos anos 1950. Isso inclui uma breve descrição da empresa e um esboço da organização e da posição do próprio sindicato da UAC: a União dos Trabalhadores Africanos da UAC da Costa do Ouro. A seção seguinte contempla o contexto político mais amplo no qual a União dos Trabalhadores da UAC (e a própria empresa) operava, particularmente no processo pelo qual o governo da CPP adquiriu o controle do movimento operário. Isso teve um claro impacto na capacidade que tinham os gestores e trabalhadores da UAC de negociar termos e condições, bem como na prática diária do trabalho. Isso será discutido na seção seguinte. Os acontecimentos após a queda de Nkrumah serão discutidos nas

11 COOPER, Frederick. Decolonization and African Society: the Labour Question in French and British Africa. Cambridge: Cambridge University Press, 1996, p. 5.

12 BECKMAN, Björn; BUHLUNGU, Sakhela; e SACHIKONYE, Lloyd(org.). Trade Unions and Party Politics. Labour Movements in Africa. Cape Town: HSRC Press, 2010; PHELAN, Craig(org.). Trade Unions in West Africa. Oxford: Peter Lang, 2011; PHELAN, Craig "Trade unions and 'responsible participation': Dahomey, 1958-1975". Labour History, v. 55, n. 3, p. 346-64, 2014; KRAUS, Jon "Strikes and labour power in Ghana". Development and Change, v. 10, p. 259-86, 1979.

13 LINDSAY, Lisa A. "Domesticity and difference: male breadwinners, working women, and colonial citizenship in the 1945 Nigerian general strike". American Historical Review, v. 104, n. 3, p. 783-812, 1999.

14 AMSDEN, Alice. International Firms and Labour in Kenya, 1945-1950. Londres: Routledge, 1971; STOCKWELL, Sarah. The Business of Decolonisation. British Business Strategies in the Gold Coast. Oxford: Oxford University Press, 2000.

15 UARM UAC/2/12/2/1/5/4 UAC Textiles Plans and Reports (1982-1987). 
seções posteriores. Os primeiros relacionam-se com o período de alternância dos governos militar e civil, entre 1966 e o início da década de 80, um período durante o qual a economia ganense deteriorou-se rapidamente e muitos trabalhadores experimentaram tempos realmente duros. Principalmente no início dos anos 1970, houve uma consciência cada vez maior das origens coloniais da UAC e de seu controle estrangeiro, o que afetou as relações entre trabalhadores africanos e a equipe europeia, que já estavam tensas devido à crise econômica. Segue-se um período revolucionário, no início dos anos 1980, quando o controle do ambiente de trabalho não apenas foi disputado entre a administração, o Estado, o sindicato, com os trabalhadores agindo independentemente do sindicato, mas também, por vezes, por Comitês de Defesa dos Trabalhadores, organizações revolucionárias e bastante poderosas. Nesse contexto, a UAC perdeu o controle de sua fábrica de estampagem têxtil, a Ghana Textile Printing - GTP. A parte final analisa como, a partir de 1983, reformas neoliberais que objetivavam estabilizar a economia enfraqueceram tanto os sindicatos quanto o Estado. Os Comitês de Defesa dos Trabalhadores desapareceram e as empresas puderam readquirir o controle administrativo. Nesse momento, a UAC foi convidada a retomar as rédeas de sua fábrica de estampagem têxtil. Essa é a parte final, não porque esse período represente o resultado final de quatro décadas de luta para dominar o ambiente de trabalho, mas porque esse é o momento em que ele desapareceu. Em 1987, a Unilever decidiu fechar as portas da UAC International (UACI, prima da empresa ganense). A partir de meados dos anos 1980, ela vendeu muitas das empresas ganenses da UAC, fechou outras e, finalmente (em 1992), integrou o restante das atividades à Unilever Gana.

\section{A UAC e seu sindicato durante os anos 50}

O ambiente de trabalho em questão, a United Africa Company, era uma subsidiária da multinacional Unilever. A UAC havia sido criada em 1929 por meio da fusão de diversas empresas comerciais pré-existentes, algumas das quais haviam sido previamente adquiridas pelos Lever Brothers, precursores da Unilever, de maneira a garantir o fornecimento de matéria-prima para a produção de sabonetes e de gêneros alimentícios. Até 1950, a UAC ainda era predominantemente uma empresa comercial, porém vinha se diversificando cada vez mais em atividades industriais e serviços, em parte, em resposta a pressões nacionalistas sobre os comércios estrangeiros a deixarem a comercialização de produtos e o comércio varejista para os africanos, e por outra parte, em antecipação a políticas de substituição das importações, e ainda por causa da expectativa de obter bons lucros. A UAC esteve ativa em diversos países africanos e também no Oriente Médio. Suas atividades eram administradas e abastecidas a partir de grandes operações na Grã-Bretanha e de algumas menores na França. Em Gana, a UAC era um importante empregador que operava numa vasta gama de setores, incluindo (dentre outros): comércio, varejo, montagem de veículos, cosméticos, estampagem têxtil e fabricação de compensados de madeira. Suas atividades não apenas abarcavam uma variedade de setores comerciais, mas também funcionavam com uma força de trabalho que incorporava escalas de competências e níveis de responsabilidade claramente distintos. Negócios como a fábrica Crocodile Matchets e a African Timber and Plywood (AT\&P), por exemplo, empregavam muito mais trabalhadores, em porcentagem da força total de trabalho, do que 
a cadeia luxuosa de lojas de departamento Kingsway, ou a de equipamentos de escritório, SAT. Todos os trabalhadores não qualificados eram africanos, assim como o eram muitos dos qualificados. A gestão, no entanto, permaneceu durante muito tempo, e em grande medida, europeia. Mesmo que as diretrizes da empresa, no sentido de uma africanização, almejassem aumentar o número de gestores africanos. ${ }^{16}$ Como consequência disso, o equilíbrio entre funcionários africanos e europeus variava dentro da organização. Desse modo, a sede, situada em Acra, que empregava, sobretudo, pessoal administrativo, contadores e gestores, tinha uma grande porcentagem de funcionários europeus, enquanto o setor de frete em barcos a remo empregava uma grande quantidade de membros do povo Kru da Libéria (e Serra Leoa). Então, a experiência de trabalhar para a UAC foi bem diferente - e muito mais diversificada - do que a de trabalhar para as ferrovias de Gana, descritas por Jeffries, ou para as minas, estudadas por Crisp. ${ }^{17}$

Os trabalhadores africanos em todas essas variadas empresas, no entanto, compartilhavam a consciência de fazerem parte da mais ampla organização da UAC. Por um lado, isso resultou da posição de relevo, e por vezes controversa, que a companhia tinha em Gana; por outro lado, do empenho consciente da empresa em desenvolver um senso de pertencimento à "família UAC"; e, por outro, da transferência periódica entre os setores de funcionários do nível de supervisor para cima. ${ }^{18}$ Durante o processo de descolonização, ao invés de se organizar nos diversos sindicatos de sua área, os empregados da UAC tinham seu próprio sindicato "doméstico", o que sugere que, para eles, a relação com esse empregador em particular prevalecia sobre a solidariedade com outros trabalhadores em cargos similares aos de fora da companhia (isso não acontecia unicamente com a UAC; outras organizações, tais como as ferrovias ou o departamento de obras públicas, também tinham seu próprio sindicato "doméstico"). Certamente, também havia bons motivos, tanto práticos quanto financeiros, para que se mantivessem nessa situação, a exemplo da relativa riqueza do sindicato da UAC e dos incentivos que a empresa oferecia ao seu sindicato. Alguns membros de outros sindicatos olhavam a escolha dos trabalhadores da UAC com desconfiança, principalmente pelo fato de o empregador em questão fazer parte de uma grande multinacional baseada na Grã-Bretanha, que mantinha laços estreitos com a administração colonial. $O$ sindicato, de fato, sentiu a necessidade de ressaltar que dependia "unicamente das contribuições recolhidas dos seus membros e que nada havia sido recebido da empresa ou de outra organização para cobrir suas imensas despesas de funcionamento. O sindicato é completamente independente". ${ }^{19}$

O Gold Coast UAC African Employees' Union (Sindicato dos Trabalhadores da UAC da Costa do Ouro) foi fundado em 1947. Até 1950, ele tinha aproximadamente três mil membros, cerca de $20 \%$ da sua força de trabalho naquele tempo, em que as categorias administrativas eram proporcionalmente sobrerrepresentadas. Ao contrário dos sindicatos mais radicais, como o dos ferroviários, ele partilhava o ponto de vista do Departamento do Trabalho da administração colonial (fortemente endossado pela administração da UAC): "Um sindicato não é uma organização com fins políticos. É uma agremiação que tem como objetivo principal a regulação das

16 "The United Africa Group's staff and labour force". UAC Statistical and Economic Review 20, p. 39-45, 1957; "Statistics". UAC Statistical and Economic Review 25, p. 62-63, 1961; "Statistics", UAC Statistical and Economic Review 29, p. 68-69, 1964.

17 JEFFRIES. Class, Power and Ideology in Ghana; CRISP. The Story of an African Working Class.

18 BERSSELAAR, Dmitri van den. "'Doorway to success?' Reconstructing African careers in European business from company house magazines and oral history interviews". History in Africa, v. 38, p. 257-94, 2011.

19 "Union holds anniversary party". Unicorn 3.5, 1957, p. 15. 
relações entre empregados e patrões." ${ }^{20}$ Em suas conferências anuais, o sindicato da UAC acolhia o diretor geral e os funcionários da UAC, assim como o comissário do Trabalho do governo colonial, e cada um tinha oportunidade de dirigir-se aos membros sindicais presentes.

A primeira conferência anual após a greve geral aconteceu em abril de 1950. Como era de se esperar, foram discutidas as questões maiores em torno do papel dos sindicatos, que tinham ganhado destaque com a greve. Na conferência, discutiu-se ainda: se o sindicato deveria se envolver com política; qual deveria ser sua atitude diante das ações grevistas; e também a relação com o TUC. Essa discussão acabou confirmando o posicionamento apolítico do sindicato. ${ }^{21}$ Claro que um posicionamento apolítico é também um posicionamento político; como se viu no ano seguinte, quando o sindicato contestou a sugestão do governo colonial de que as empresas reconsiderassem recontratar os trabalhadores que haviam sido demitidos durante a campanha de Ação Positiva. ${ }^{22}$ Além disso, a liderança sindical gozava de uma relação estreita com a administração da UAC, que por sua vez facilitava e apoiava o desenvolvimento do sindicato. ${ }^{23}$ Nas conferências sindicais, os membros eram lembrados que "se os trabalhadores dessem o máximo de sua produtividade, os patrões iriam considerar dar-lhes a devida remuneração"..24 Conflitos entre sindicalistas e patrões certamente ocorreram. Porém, o sindicato e a empresa mantinham um acordo que, a princípio, tais conflitos não seriam publicizados, ao contrário, seriam resolvidos por meio da hierarquia sindical. Recordava-se aos sindicalizados que, "se, a qualquer tempo, os membros sentissem que havia determinada condição de serviço de que não gostassem, o assunto deveria ser reportado ao secretário regional, que tentaria solucionar o caso por caminhos ortodoxos; os indivíduos não deveriam acionar a imprensa". 25

Isso, no entanto, não impediu agravamentos ocasionais de disputas trabalhistas, por vezes resultando em extensa cobertura jornalística. Como exemplo disso, em 1958, quando a diretoria da UAC decidiu transferir A. O. Mensah da divisão de abastecimento e transporte de carvão, em Takoradi, para o ferry do outro lado do rio Volta, em Ada, seus colegas fizeram greve para forçar a empresa a reverter a transferência. Mensah era o presidente do sindicato da UAC regional. A diretoria assumiu uma linha dura: Mensah foi informado que, em caso de não apresentação em Ada, ele poderia considerar seu mandato encerrado. Aos outros trabalhadores foi informado que, se alguém aderisse à greve, isso seria considerado abandono do emprego. Apesar de tais ameaças, cerca de metade da força de trabalho do setor de transporte (UAC Lighterage) em Takoradi aderiu à greve. Esta durou onze dias e foi bastante noticiada na imprensa nacional. Após oito dias de greve, vinte e cinco sindicatos afiliados ao Conselho Sindical SekondiTakoradi fizeram uma manifestação a fim de demonstrar apoio aos trabalhadores da UAC Lighterage e funcionários de diversas outras empresas aderiram à greve por solidariedade. ${ }^{26} \mathrm{~A} U A \mathrm{C}$ recusou-se a negociar com seu sindicato, e a paralisação só chegou ao fim por intervenção do Ministério do Trabalho e Cooperativas, que

20 JEFFRIES. Class, Power and Ideology in Ghana, p. 40 (Jeffries está citando "um panfleto escrito pelo conselheiro especial do Departamento do Trabalho do Quênia, que foi amplamente divulgado aos organizadores sindicais em todo o Reino Unido").

21 "UAC African Union holds its annual conference". Gold Coast UAC News 1.5, 1950, p. 3.

22 DECKER. "Building up Goodwill", p. 218.

23 "Tarkwa weekend education conference". Gold Coast UAC News 2.9, 1951, p. 1.

24 "Winneba weekend education conference". Gold Coast UAC News 3.4, 1951, p. 1.

25 "Accra District Union confers". Gold Coast UAC News 2.10, 1951, p. 1.

26 ASILIJOE, E. K. "250 Harbour Workers go on Strike". Daily Graphic, 5 fev. 1958; ASILIJOE, E. K. "Trade Council Warning". Daily Graphic, 8 fev. 1958; ALANDO, Nicholas. "3-Hour P\&T Strike". Daily Graphic, 12 fev. 1958. 
ordenou aos grevistas retomarem seus postos de trabalho. A UAC não voltou atrás em sua decisão de transferir Mensah, mas concordou em recontratar os que aderiram à greve. ${ }^{27}$

O resultado da greve de 1958 ilustra bem as transformações que ocorreram no movimento sindical desde a greve geral de 1950, bem como as mudanças de atitude do governo ganense com relação às questões trabalhistas. Como em muitos países africanos, o governo ganense havia reorganizado os sindicatos em um corpo nacional controlado pelo Estado, e depois se utilizou desse corpo para forçar os sindicatos a serem menos "egoístas" ao defenderem os interesses dos seus membros, e a serem mais "responsáveis", abraçando os objetivos nacionais ao reduzir o número de greves e manter um aumento da produtividade. ${ }^{28} \mathrm{O}$ resultado final foi um movimento operário ligado ao Estado e comprometido em contribuir para alcançar as metas econômicas e políticas formuladas pelo governo. Fundamentalmente, fazê-lo requeria minimizar as reivindicações dos trabalhadores, ou até mesmo ir contra seus interesses. Embora seja bem conhecido o processo geral pelo qual governos independentes adquiriram controle do movimento sindical, sabe-se menos sobre o impacto de tais esforços sobre os sindicatos e ambientes de trabalho em nível local.

\section{Política, Estado e movimento sindicalista na Gana independente}

A greve geral de janeiro de 1950 teve consequências de grande amplitude. Em termos de política nacionalista, a campanha de "Ação Positiva" de desobediência civil que ela desencadeou ajudou a alcançar as reivindicações que os políticos nacionalistas faziam ao governo colonial. Embora Kwame Nkrumah e muitos apoiadores de seu movimento, a Convention People's Party (CPP), tenham sido detidos e encarcerados, a campanha ajudou a criar uma constante pressão anticolonial. Na perspectiva da independência oficial, os britânicos organizaram eleições gerais para uma nova Assembleia Legislativa e um novo governo em fevereiro de 1951. Nessas eleições, venceu a CPP, e Nkrumah foi libertado da prisão, formando um governo logo na semana seguinte. Chefe de um gabinete da CPP, Nkrumah tornou-se o líder dos negócios governamentais (a partir de 1952, tornouse primeiro-ministro) da colônia da Costa do Ouro. Quando Gana tornou-se uma nação independente em 1957, a CPP manteve-se no poder e Nkrumah permaneceu primeiro-ministro (em 1960, tornou-se presidente). Nkrumah e a CPP beneficiaramse claramente do apoio sindical e, particularmente, do impacto da greve de 1950.

Para o próprio movimento sindical, todavia, o efeito da greve foi devastador. Richard Jeffries observou que a greve praticamente destruiu o TUC da Costa do Ouro e muitos dos seus sindicatos membros, mas que o dos mineradores e o dos empregados da UAC, que não apoiaram a greve, foram menos afetados. $O$ Ministério do Trabalho colonial então reformou o TUC em torno desses sindicatos moderados, apolíticos. Uma nova constituição proibiu o TUC de iniciar paralisações gerais e deu ao Ministério do Trabalho poderes de supervisão do uso dos fundos do TUC. Subsídios foram encaminhados por meio do British Council para que

27 UARM UAC/1/11/3/3/7 Ghana News Agency Telex, 14 fev. 1958; "UAC strikers go back today"». Daily Graphic, 15 fev. 1958.

28 PHELAN. "Trade unions and 'responsible participation'", p. 347. 
representantes sindicais viajassem à Grã-Bretanha para estudar procedimentos sindicais. ${ }^{29}$ Durante um breve período, o Sindicato dos Trabalhadores da UAC achouse em pleno centro do movimento sindical da Costa do Ouro, e seu secretáriogeral, Samuel Larbi-Odam, também ocupava o cargo de presidente do TUC. ${ }^{30}$

Nascido em 1923, Larbi-Odam empregou-se na UAC em 1943, aos 19 anos de idade, como escriturário no setor da empresa que lidava com compra nas principais áreas de produção de cacau. Em 1950, tornou-se secretário permanente do Sindicato dos Trabalhadores Africanos da UAC Costa do Ouro, em tempo integral. Nesse tempo, em meio ao movimento sindical, o seu sindicato, sendo "da casa", mantinha a reputação de ser conservador. Os trabalhadores da UAC, na sua maior parte funcionários de "colarinho-branco", gozavam de melhores condições do que a maioria, e eram frequentemente vistos como sendo mais leais à empresa do que ao movimento trabalhista, ainda incipiente. Do ponto de vista do governo colonial, isso o tornava um "sindicato moderado". O título de um dos artigos opinativos de Larbi-Odam num dos principais jornais ganenses, "Não adianta insultar os patrões", resume bem o posicionamento do seu sindicato. ${ }^{31} \mathrm{Em}$ 1951, Larbi-Odam assumiu o cargo de secretário permanente do TUC, tornando-se um dos indivíduos mais importantes do movimento operário de Gana. Mas isso não durou muito. Em 1953, como parte de uma reorganização complexa do movimento sindical articulada pela CPP, ele foi substituído na chefia do TUC por um colaborador de Nkrumah, John Tettegah, que também havia trabalhado para a UAC antes de se tornar sindicalista em tempo integral. Larbi-Odam foi vítima da purga efetuada pelo governo dos chamados "agitadores sindicalistas esquerdistas", muito embora ele estivesse, é claro, muito longe de ser de esquerda, e certamente não era um agitador. ${ }^{32}$ No entanto, continuou a liderar o sindicato dos trabalhadores da UAC e o removeu do âmbito do TUC porque a estrutura deste, cada vez mais centralizada, ameaçava privar o sindicato de muito do seu poder de barganha. ${ }^{33}$ Nos anos seguintes, o governo da CPP pressionou bastante o sindicato da UAC para que retornasse ao seio do TUC, usando de legislação sindical, pressões políticas e negociações em separado, além de fazer campanhas na mídia popular. Quando o sindicato da UAC foi forçado a ceder e retornou ao TUC, no final de 1959, a imprensa, que era controlada pelo governo, noticiou que "o Sindicato, cuja liderança foi a um tempo temida por estar nas mãos da tão poderosa Unilever, juntou-se às fileiras. Que isso prove a síntese mais completa graças a mais plena cooperação, DISCIPLINA, lealdade e sinceridade em todos os lados."34 Em maio de 1960, Larbi-Odam foi obrigado a se demitir do seu cargo de secretário-geral da então chamada UAC Workers Division of the Commercial and Allied Workers Union of the TUC (Divisão dos Trabalhadores da UAC do Sindicato dos Comerciários e afins, do TUC), e foi expulso do sindicato. ${ }^{35}$ De volta à UAC, foi promovido a um cargo de diretoria na primeira oportunidade, em janeiro de 1961, e continuou sua carreira como funcionário da empresa Unilever.

29 JEFFRIES. Class, Power and Ideology in Ghana, p. 58.

30 "Mr S. L. Odam at Margate". Gold Coast UAC News 3.10, 1952, p. 2.

31 "'Insulting the Bosses Won't Help' Says S. Larbi Odam, General Secretary, UAC Employees' Union". Daily Graphic, 18 out. 1956.

32 AGYEMAN, Opoku. The Failure of Grassroots Pan-Africanism: The Case of the All-African Trade Union Federation. Lanham, 2003, p. 347.

33 NUGENT, Paul. Africa since Independence. A Comparative History. Basingstoke: Palgrave, 2004), p. 174; JEFFRIES. Class, Power and Ideology in Ghana, p. 66.

34 "Welcome UAC Union!!!". Evening News, 16 out. 1959; ver também: "UAC Union Surrenders". Ghana Times, 16 out. 1959.

35 "Larbi Odam Resigns Secretaryship". Ashanti Pioneer, 2 maio1960; "Odam Expelled". Ghana Times, 5 maio 1960. 
O governo da CPP, liderado por Kwame Nkrumah, deveu sua existência, ao menos em parte, conforme vimos, às ações das greves em favor do nacionalismo. Uma vez no poder, contudo, a CPP veio a considerar a independência e o radicalismo dos sindicatos com desconfiança e tentou estabelecer o controle do TUC designando representantes sindicais leais ao partido. Já observamos como a CPP veio a nomear John Tettegah, um colaborador aliado de Nkrumah, como chefe do TUC. Tettegah representava um tipo de sindicalista bem diferente de Larbi-Odam. Nascido em 1930, ele também iniciou sua carreira na UAC como datilógrafo na subsidiária G. B. Ollivant, que lidava com varejo. Tornou-se ativo no sindicato da empresa, vindo a ser o seu secretário-geral aos 19 anos, em 1949 (segundo ele), ou em 1951. Em 1952, fundou e foi secretário-geral da Mercantile Workers' Federation (Federação dos Trabalhadores Mercantis), uma organização que, diz-se, existia "mais no papel do que na realidade". ${ }^{36}$ Enquanto Larbi-Odam foi e continuava a ser um funcionário leal (embora crítico) da UAC, Tettegah focava nas suas próprias ambições políticas desde o início, usando de suas habilidades organizacionais para construir o movimento operário como uma base de poder que pudesse torná-lo útil para a liderança da CPP de Nkrumah. Foi nomeado secretário-geral do TUC em 1953 e usou dessa posição para subordinar o movimento sindical à CPP. Serviu ao partido e se promoveu. Ganhando muito bem e vivendo no luxo, perdeu o contato com os trabalhadores que deveria representar. Ele enxergou nitidamente seu futuro político na CPP, mais do que como um líder sindical. Quando o governo de Nkrumah foi deposto por um golpe militar em 1966, Tettegah foi preso. Após sua libertação, não retornou à liderança do movimento sindical. Tettegah representava uma nova espécie de agente aliado a CPP e ao TUC: além de motivados pela lealdade a CPP, pelas preocupações com as tribulações dos trabalhadores e pelo compromisso com o desenvolvimento de uma economia nacional industrializada, eles também pretendiam elevar o seu status político e financeiro.

Desse modo, no período entre 1954 e 1955, o TUC perdeu sua relativa independência política. Introduzindo uma estrutura hierárquica no sindicato, e uma sede do TUC bem financiada e provida de bons funcionários, o governo procurou transformar o ambiente de trabalho ganense, bem como o movimento operário, numa plataforma de apoio à CPP. O Sindicato dos Trabalhadores da UAC não foi o único a deixar o domínio do TUC em resposta a essas mudanças. Quando outros sindicatos, incluindo o dos trabalhadores ferroviários, igualmente optaram por atuar fora do TUC, o governo decidiu reforçar a "nova estrutura" pela via legal. O Industrial Relations Act de 1958 determinava que toda negociação entre sindicatos e empresas deveria ser conduzida por meio do TUC de Gana em nome dos 24 sindicatos constituintes, tornando-o responsável pela condução direta de todas as maiores questões sindicais. Essa determinação fortaleceu o poder dos burocratas do TUC e obrigou os sindicatos externos a ele a se reafiliarem. ${ }^{37}$

36 BERG, Elliot J.; BUTLER, Jeffrey. "Trade unions". In: ROSBERG JR., Carl G.; COLEMAN, James S. (org.). Political Parties and National Integration in Tropical Africa. Berkeley, 1964, p. 359, n. 20.

37 NUGENT. Africa since Independence, p. 174; JEFFRIES. Class, Power and Ideology in Ghana, p. 66-7. 


\section{O impacto dos anos Nkrumah sobre o ambiente de trabalho da UAC}

Esses empenhos para controlar o movimento sindical em nível nacional surtiu um grande efeito no sindicato da UAC em suas relações com a empresa e nos ambientes de trabalho regionais. Muita pressão foi colocada sobre a liderança do sindicato da UAC, suas filiais e nos seus membros para afiliarem-se ao TUC. Na imprensa nacional, o Sindicato dos Trabalhadores da UAC foi descrito como "diabólico", enquanto Larbi-Odam, nesse momento ex-presidente do TUC e ainda secretário-geral do Sindicato da UAC, foi acusado de "despotismo" e de espalhar "uma propaganda insidiosa contra o governo". ${ }^{38}$ Tettegah, como secretário-geral do TUC, comentou que Larbi-Ordam e outras lideranças sindicais da UAC eram "ditadores" e "se contrapunham ao destino dos trabalhadores ganenses". 39

Enquanto fustigava o sindicato da UAC como "inimigo dos trabalhadores", o governo da CPP e a imprensa aliada teciam elogios à administração da UAC por seu comprometimento com os sindicatos. Num artigo intitulado "Economia colonial", duramente crítico ao comércio estrangeiro em Gana, a UAC é elogiada como "um brilhante exemplo para outros empregadores seguirem". ${ }^{\circ}$ Os que criticavam o governo, da mesma forma elogiavam a gestão da UAC, mas ao invés de opor administração e trabalho, louvava-se a colaboração bem sucedida entre um patrão receptivo e um sindicato competente. Preconizava-se que o governo seguisse o exemplo da UAC. Invertendo o discurso de Nkrumah, seus detratores apresentavam a empresa estrangeira como a portadora da justiça e liberdade, e acusavam o "governo pan-africano de Gana" de ser um "mau governo" que estava dando continuidade aos dias de imperialismo e não dava atenção às necessidades dos trabalhadores. De fato: "Os trabalhadores de Gana têm que ser auxiliados assim como a UAC ajudou os seus empregados." 41

Ao mesmo tempo em que o governo da CPP e o TUC de um lado, e os críticos das políticas da CPP de outro, buscavam implicar e envolver a gestão da UAC no conflito, a empresa desesperava-se para permanecer fora dele. Quando o setor financeiro da empresa implantou o sistema legalizado de "desconto na folha" (das contribuições sindicais a serem entregues ao TUC), ficou evidente que a empresa apoiava a "nova estrutura" e estava satisfeita que seu sindicato fizesse parte de uma confederação nacional. ${ }^{42}$ Enquanto isso, a gestão da empresa estava na corda bamba: por um lado, desesperava-se para ficar fora do debate e afirmava repetidamente que cabia aos trabalhadores decidir como queriam se organizar, e que negociaria com qualquer agremiação que os representasse. Por outro lado, precisava manter boas relações com o governo da CPP a fim de seguir fazendo negócios em Gana. E, nesse sentido, ela foi bem sucedida: mesmo em tempos de forte retórica do governo contra empresas estrangeiras, a UAC teve várias oportunidades para implantar novos negócios e expandir os já existentes. ${ }^{43}$

\footnotetext{
38 "UAC Workers Revolt Against Odam's Despotism. Takoradi TCLC Secedes". Ghana Evening News, 7 out. 1955; "Editorial: a big slap". Guinea Times, 14 maio 1958; "They secede from UAC union". Ghana Times, 14 abr. 1959; "UAC 'house' union splits, majority hop into TUC fold". Accra Evening News, 23 abr. 1959.

39 "UAC Union An Enemy To Workers". Accra Evening News, 18 out. 1958.

40 "Colonial Economy". Daily Graphic, 24 abr. 1957.

41 "UAC". Liberator, 8 ago. 1957.

42 "Ghana UAC approves check-off". Ghana Evening News, 15 mar. 1958.

43 FIELDHOUSE. Merchant Capital and Economic Decolonization, p. 503-38.
} 
É claro que as primeiras décadas após a greve geral de 1950 foram tensas para o movimento operário em Gana. Embora a independência tenha sido alcançada, os trabalhadores não contaram com o apoio do Estado ganense independente. Consciente do potencial revolucionário do trabalhador organizado, o governo do CPP reorganizou o movimento sindical em um órgão que o apoiava e a suas políticas. Em vez de representar as demandas dos trabalhadores, o TUC e seus ramos constituintes lhes impuseram as prioridades governamentais. As greves foram desencorajadas e o foco foi colocado na produtividade: o trabalho deixou de ser apenas um intercâmbio econômico entre trabalhador e empregador para tornar-se um dever patriótico. Essa ênfase foi, naturalmente, o resultado das políticas de desenvolvimento econômico iniciadas no governo Nkrumah e que visavam a industrialização do país, em grande parte agrícola, mediante a criação de novas indústrias, infraestrutura portuária e rodoviária e do projeto hidroelétrico da Volta Dam. O aumento da produtividade foi alcançado em muitos outros países mediante um acordo em que os trabalhadores concordaram em aumentar a produção em troca de salários mais elevados - estratégia que, como se supõe acima, a UAC estava preparada para assumir. ${ }^{44}$ No caso de Gana (e de vários outros estados pós-coloniais africanos) essa opção não foi colocada na mesa. Foi por outro caminho que o governo de Nkrumah, apesar de suas críticas oficiais a negócios estrangeiros, apoiou os negócios na pressão para o aumento da produtividade, embora pretendesse manter os salários baixos e suprimir as ações de greve. Essa situação não mudou após a queda do governo Nkrumah em 1966. Para as empresas - pelo menos para a UAC - foi uma faca de dois gumes, na melhor das hipóteses, na medida em que a politização do ambiente de trabalho foi também desestabilizadora.

Para os trabalhadores, dada sua experiência com os sindicatos e o papel de membros do partido do CPP e o uso governamental da Confederação Sindical, a qual seus sindicatos foram forçados a pertencer, e as consequentes tensões e politização do ambiente de trabalho, os riscos de engajamento eram muitas vezes superiores aos potenciais benefícios. Isso não quer dizer que não houvesse algum envolvimento individual com sindicatos: os trabalhadores da UAC continuaram a ser membros dos sindicatos organizados pelo setor nacional (dado que o sindicato de "casa" da empresa já não existia) e esses sindicatos ocasionalmente conseguiram pressionar o governo. ${ }^{45}$ Muitos outros trabalhadores ocasionalmente participaram de ações de greve (muitas vezes não oficiais).

\section{O impacto no ambiente de trabalho da UAC durante}

\section{os anos 1970}

A queda de Nkrumah foi seguida por anos de instabilidade política e econômica. O primeiro governo pós-Nkrumah foi o do Military National Liberation Council - NLC (Conselho Militar de Libertação Nacional), sucedido, em 1969, pelo governo civil de Busia, de curta duração. Em 1972, os militares voltaram ao poder com o chamado National Redemption Council (NRC) e, mais tarde, Supreme Military Council - SMC (Supremo Conselho Militar). Um novo golpe militar, em

44 WILSON, John F.; THOMSON, Andrew. The Making of Modern Management. British Management in Historical Perspective. Oxford: Oxford University Press, 2006, p. 79.

45 KONINGS, Piet. "Structural adjustment and trade unions in Africa: The case of Ghana". In: JIBERTO, Alex Fernandez; RIETHOF, Marieke (org.). Labour Relations in Development. Londres: Routledge, 2002, p. 313. 
1979, levou ao rápido governo do Armed Forces Revolutionary Council - AFRC (Conselho Revolucionário das Forças Armadas), que entregou a Limann no mesmo ano. O governo de Limann durou até outro golpe militar, em 1981, que levou ao poder o Provisional National Defence Council - PNDC (Conselho Provisório de Defesa Nacional) liderado por Rawlings. Ao longo desses anos, a economia ganense deteriorou-se. Os governos tentaram várias políticas econômicas, nenhuma delas impediu seu declínio. Controles cambiais contribuíram para a escassez de bens importados no país, mas não impediu a desvalorização da moeda ganesa, cedi. As indústrias locais produziram abaixo da capacidade devido à falta de matérias-primas importadas. Os trabalhadores experimentaram aumento do custo de vida, diminuição dos salários reais e falta de perspectivas para o futuro. $\mathrm{O}$ descontentamento foi expresso em protestos e, em menor grau, greves. ${ }^{46}$

Fora um breve período, entre 1971 e 1972 (com a proibição do TUC pela administração de Busia, porque era um resquício da era de (PP), a organização do movimento sindical criada por Nkrumah foi mantida. ${ }^{47}$ A liderança nacional do TUC assumiu uma posição conformista, reformista e apolítica. Prometeu cooperar com o governo, controlar a organização de base e se opor às greves, em troca do apoio do governo a certas demandas sindicais e da representação do TUC nos conselhos e comitês públicos. Os governos demonstraram pouca vontade de levar em conta as preocupações dos líderes do TUC e tensões apareceram entre a liderança nacional do TUC e os sindicatos locais, levando a secessões (temporárias) e tentativas de restabelecer alguns sindicatos das "casas"..$^{8} \mathrm{O}$ sindicato da UAC não foi reestruturado e os trabalhadores na maioria dos negócios da UAC continuaram sendo representados pelo Sindicato dos Trabalhadores Industriais e Comerciais (UTI) do TUC. No entanto, devido à intervenção direta do governo nas questões trabalhistas, o sindicato teve oportunidades limitadas de negociar termos e condições. Isso foi frustrante tanto para os membros do sindicato quanto para a gestão da UAC.

Os sucessivos governos fizeram concessões aos trabalhadores quando assumiram o poder, mas depois tentaram manter os salários baixos como parte de tentativas geralmente mal sucedidas de controlar a inflação. ${ }^{49} \mathrm{Em}$ intervalos regulares durante a década de 1970, a administração da UAC sentiu que um aumento de salário teria sido justificado em vista do aumento do custo de vida, mas a empresa não foi capaz de levá-lo a cabo. Entretanto, o governo desencorajou os trabalhadores a entrarem em greve. Embora a linha oficial fosse que "o governo considera o TUC uma organização importante que representa os interesses dos trabalhadores do país daí sua ajuda persistente a ela", igualmente "aconselhou os trabalhadores de Gana a negociar suas insatisfações mediante procedimentos estabelecidos como conciliação e negociações, em vez de recorrer a paralisações e greves"..$^{50} \mathrm{E}$ como se isso não estivesse suficientemente claro, os representantes regionais enfatizaram que "Gana não pode, nessa fase de seu desenvolvimento e progresso, tolerar greves industriais e intenções divisórias que tendem a retardar a marcha do país". ${ }^{51}$ Permanecia a ideia do dever patriótico separado da questão da

46 Isso é bem conhecido e tem sido efetivamente resumido em muitos estudos do período. Para uma boa visão geral, ver: GOCKING. The History of Ghana, p. 147-89; Estatísticas sobre a ocorrência de greves entre 1945 e 1976 são dadas por KRAUS. "Strikes and labour power", p. 265.

47 RIMMER, Douglas. Staying Poor. Ghana's Political Economy 1950-1990. Oxford: Pergamon Press, 1992, p. $109 ; 134$.

48 KRAUS. "Strikes and labour power", p. 270-71.

49 GOCKING. The History of Ghana, p. 173.

50 "Workers asked to resist strikes". Ghanaian Times, 4 jul. 1974.

51 NAYKENE, George. "No industrial strikes says Lt. Col. Habada". Daily Graphic, 29 out. 1974. 
remuneração. Durante a "Operation feed your factory" (manter a sua fábrica), por exemplo, era esperado que se trabalhasse voluntariamente (sem remuneração) aos sábados como contribuição para a reanimação da economia do país. ${ }^{52}$

Os regimes que se sucederam fizeram uso pesado da legislação antigreve para processar seus líderes e, às vezes, os reprimiram violentamente. ${ }^{53} \mathrm{Em}$ março de 1971, uma greve na filial UAC's African Timber and Plywood (AT\&P), em Samreboi, tomou a gerência da UAC de surpresa. A intervenção policial deixou dois trabalhadores mortos e três feridos. Um relatório do gerente de pessoal identificou como causas da greve os baixos salários pagos em Gana e o aumento do custo de vida, ao lado de uma consciência de que recentes e violentas greves em outros setores haviam terminado com demandas dos trabalhadores atendidas pelo governo e "a impressão de que se a força fosse usada, as exigências dos trabalhadores seriam atendidas". ${ }^{54} \mathrm{~A}$ greve foi uma ação informal dos trabalhadores e não tinha sido apoiada pelo sindicato. Os diretores da UAC simpatizavam com as demandas dos trabalhadores. Eles concordavam que os salários pagos pela empresa estavam muito baixos por causa da inflação. No entanto, eles tinham sido impedidos de aumentar os salários porque "infelizmente nossas taxas estavam ligadas às do Timber Trade Union (Sindicato do Comércio de Madeira)". ${ }^{55}$ Além das regulamentações governamentais oficiais que a empresa era obrigada a cumprir, a UAC constatou que seu controle sobre o ambiente de trabalho estava ainda mais reduzido pela arbitrariedade de administrações essencialmente autoritárias, expressas por meio de "uma tendência crescente de vários funcionários do governo dar instruções como se tivessem força legal para tal". ${ }^{56}$

Uma característica da década de 1970 foi o endurecimento do discurso político contra as empresas estrangeiras. Os governos introduziram uma série de medidas para apoiar os empresários ganenses e forçar as empresas estrangeiras a abrir totalmente ou parte do seu capital a investidores ganenses. Tais medidas impactaram a UAC, mas, além de influenciar o tom da conversa, não afetaram as lutas no ambiente de trabalho, já que a introdução de novos acionistas não mudou a gestão diária do negócio. Mais importante do que isso foi o renovado foco na africanização da gestão. A partir de 1970, os contratos de condições de serviço que a empresa negociou com os sindicatos incluíam uma cláusula de africanização (posteriormente ghanaianisation), especificando que: "O empregador deve assegurar que os postos administrativos e técnicos estejam disponíveis para ganenses qualificados e todas as instalações devem estar ligadas a esses postos". ${ }^{57}$ A presença contínua de gestores europeus poderia, assim, criar tensões.

Em 30 de abril de 1975, funcionários da fábrica Crocodile Matchets da UAC, em Tema, pararam o trabalho e organizaram um protesto contra o gerente de obras. Numa declaração escrita, os trabalhadores explicaram que não tinham confiança no seu único gerente expatriado e se opuseram ao seu comportamento: "Gostaríamos de descrever a sua atitude em relação aos empregados como escravidão"..$^{58}$ Alegaram também que o gerente de obras carecia de conhecimento técnico e que os técnicos locais de Gana haviam sido responsabilizados pelos danos causados por ele; além disso, que o gerente comercial havia ignorado reclamações

52 EYI-MENSAH, Bob. "1,700 workers give free labour". Daily Graphic, 7 jul. 1974.

53 KRAUS. "Strikes and labour power", p. 262.

54 Unilever Ghana Archive (UGA) HRD BOX111 Report on Samreboi Riots (AT\&P) (1971).

55 UARM UAC/1/1/1/2/29 UAC Ltd Minute Book 26, p. 29 (Board Meeting 6 abr. 1971).

56 UARM UAC/1/1/1/2/26 UAC Ltd Minute Book 23, p. 63 (Board Meeting 21 maio 1968).

57 UGA HRD BOX148 Conditions of Service Agreements 1969-1980.

58 UGA HRD BOX148 Conditions of Service Agreements 1969-1980. 
anteriores contra o gerente de obras. De acordo com o gerente comercial, ele próprio ganês, a verdadeira razão da insatisfação com a administração foi o aumento da vigilância contra roubos: altos funcionários, incluindo funcionários da União haviam roubado machetes da fábrica e pelo menos quatro funcionários foram capturados e condenados. Os roubos, no entanto, continuaram, e a administração alegou que os trabalhadores e os dirigentes sindicais estavam a aproveitar-se do rancor em relação aos estrangeiros na sociedade ganense para tentar se livrar de um gerente que estava "tornando as coisas difíceis para os ladrões na fábrica". 59 Os registros neste caso não revelam quais dos dois lados, talvez ambos, estavam corretos em suas afirmações.

Ao longo da existência da UAC, seus funcionários haviam roubado bens e muitos foram capturados e condenados. Ao mesmo tempo, há também casos documentados de gestores estrangeiros que tratavam os trabalhadores locais com desrespeito. Por exemplo, quando um gerente de um dos centros comerciais da Kingsway UAC supostamente esbofeteou uma funcionária quando a instruía a arrumar um tapete no andar de vendas, o sindicato exigiu que o gerente fosse demitido da empresa e expulso do país, e ameaçou uma greve caso não fossem atendidos. $^{60}$

No final da década de 1970, a relação entre governo, empresas e trabalhadores deteriorou-se ainda mais, alinhado com o contínuo declínio da economia de Gana. Entre 1970 e 1981, o PIB per capita diminuiu mais de 30\%, enquanto a produção de cacau, maior fonte de divisas estrangeiras, caiu pela metade. ${ }^{61}$ A flutuação da inflação, o aumento do custo de vida, a limitação da correção dos salários e a escassez de bens disponíveis para venda levaram a indesejáveis ondas de greves, que o governo reprimiu de forma muito severa. ${ }^{62} \mathrm{Um}$ dos diretores da UAC relatou que "as [c]ondições em Gana eram muito tristes. Nenhum bem de consumo estava entrando no país e era com dificuldade que as pessoas conseguiam sobreviver".63 Para a UAC, as condições comerciais eram "muito difíceis", com poucas oportunidades de importação de mercadorias para venda em seus empreendimentos comerciais, matérias-primas para produção em suas fábricas ou peças sobressalentes para manter seus equipamentos. ${ }^{64}$ Experimentou, além disso, agitação operária que interrompia a produção nas cervejarias e nos setores têxteis. ${ }^{65} \mathrm{~A}$ economia em declínio e a natureza severa e intervencionista do Estado ganês, gradualmente, minaram o controle administrativo da UAC sobre o ambiente de trabalho. Na sequência dos muitos novos projetos criados durante as décadas de 1950 e 1960, a década de 1970 assistiu ao escasseamento do investimento da UAC em Gana. Em vez disso, a empresa tentava conter os custos mantendo a integridade de suas estruturas na expectativa de uma futura melhoria das condições. ${ }^{66} \mathrm{~A}$ UAC passou por várias rodadas de contenção, considerando que milhares de trabalhadores eram desnecessários, mas, no entanto, mantinha essa mão de obra sobressalente. Como resultado, na década de 1970, houve menos incentivos e menos oportunidades de formação e promoções de pessoal e, em

59 UGA HRD BOX148 Carta de W. E. Inkumsah, Commercial Manager Crocodile Matchets (Ghana) Ltd., para Commissioner for Labour \& Co-operatives, 23 maio 1975.

60 UARM UAC/1/1/1/2/22 UAC Ltd Minute Book 19, p. 140 (Minutes of Board Meeting 15 set. 1964).

61 KONINGS. "Structural adjustment and trade unions", p. 314.

62 GOCKING. The History of Ghana, p. 178-86.

63 UARM UAC/1/1/1/2/38 UACI Minute Book 35, p. 21 (Minutes of Board Meeting 19 fev. 1980).

64 UARM UAC/1/1/1/2/36 UACI Minute Book 33, p. 68 (Minutes of Board Meeting 4 jul. 1978).

65 UARM UAC/1/1/1/2/36 UACI Minute Book 33, p. 85 (Minutes of Board Meeting 15 ago. 1978); p. 94 (Minutes of Board Meeting 5 set. 1978).

66 UARM UAC/2/20/1/5/3/4 Jocelyn G. Clark to G. H. Wilson, 18 jul. 1980. 
1980, a empresa observou que a "falta de competitividade" e de oportunidades de promoção haviam resultado no declínio dos padrões profissionais e níveis de desempenho. ${ }^{67} \mathrm{~A}$ consequente debilidade das gerências intermediárias encontrou dificuldade para resistir às pressões dos trabalhadores, sindicatos e funcionários do governo, o que enfraqueceu o controle gerencial sobre o ambiente de trabalho.

\section{O ambiente de trabalho e os Comitês de Defesa dos Trabalhadores}

A fase seguinte da luta pelo controle do ambiente de trabalho ocorreu em 1982. Em 31 de dezembro de 1981, um golpe militar levou o tenente Rawlings ao poder. Não era a primeira vez, Rawlings também tinha liderado o golpe anterior em 1979, quando rapidamente transferiu o poder a um governo civil. Dessa vez ele decidiu ficar. O Provisional National Defence Council - PNDC começou como um governo revolucionário neomarxista que pretendia romper com as relações neocoloniais e acabar com o controle estrangeiro sobre a economia. A Revolução de 31 de Dezembro foi apoiada por uma série de movimentos políticos radicais, que incluíam estudantes e professores universitários, oficiais de baixa patente do exército e sindicalistas. Estes também atuaram na organização dos Workers' and People's Defence Committees (Comitês de Defesa dos Trabalhadores e do Povo), que garantiram apoio popular ao governo revolucionário.

Dentro das empresas, os Comitês de Defesa dos Trabalhadores operavam ao lado dos sindicatos e da administração. Eles asseguravam o direito de cada cidadão exercer seu poder no processo de tomada de decisão, ao contrário da situação anterior à revolução, quando o poder esteve sempre nas mãos dos poucos privilegiados que constituíam a liderança sindical ou a gestão da empresa. De acordo com o presidente do Comitê de Defesa dos Trabalhadores (WDC) da Divisão GCMT da UAC, "a revolução não era contra a administração, mas se qualquer gerente tentasse a tática de dividir para reinar, seria impedido de fazêlo". ${ }^{68}$ Ele explicou que a função do comitê "era defender os trabalhadores em seus locais de trabalho, a fim de garantir que as coisas andassem bem".

Isso naturalmente levantava a questão de se ainda havia lugar para os sindicatos na nova Gana revolucionária. O governo do PNDC favoreceu os Comitês Revolucionários de Defesa dos Trabalhadores em detrimento do movimento sindical, que considerava egoísta por exigir concessões para os já privilegiados empregados urbanos na economia formal, ao custo do trabalho duro e sofrido de todos os outros ganenses. ${ }^{69}$ No entanto, de acordo com o presidente do GCMT/WDC, havia um lugar para os sindicatos: os dirigentes sindicais negociariam os benefícios dos trabalhadores, etc. Caso houvesse algo que eles achassem extremamente difícil de lidar, então o WDC cuidaria do assunto. ${ }^{70}$

Embora os Comitês de Defesa dos Trabalhadores fossem organizações ostensivamente de base, eles estavam organizados hierárquica eburocraticamente: "Um memorando recebido de nosso gerente administrativo, Accra, o WDC na sede da UAC, Swanmill Accra escreveu a todas as divisões sob a égide do UAC Ghana

67 UARM UAC/2/20/1/5/3/4 J. A. Hickin, Provisional Personnel Strategy 1980-1981/1984-1985 (Accra, 23 abr. 1980).

68 UGA HRD BOX148 Minutes of Workers Defence Committee, GCMT Division, Nsawam, 7 fev. 1983.

69 KONINGS. "Structural adjustment and trade unions", p. 323.

70 UGA HRD BOX148 Minutes of Workers Defence Committee, GCMT Division, Nsawam, 7 fev. 1983. 
para realizar reuniões gerais da WDC em datas determinadas de cada mês ao longo do ano". ${ }^{71} \mathrm{Na}$ prática, os Comitês de Defesa dos Trabalhadores também tentaram minar o poder dos sindicatos e da administração da empresa: "Se houvesse alguma coisa acontecendo em qualquer departamento da organização, deveríamos tentar destruí-los em seus estágios iniciais, em vez de encaminhá-las à administração. Minando nossa gestão eles tomam nossos lugares."72 De fato, no caso da Ghana National Trading Corporation (que não faz parte da UAC), os Comitês de Defesa dos Trabalhadores conseguiram a remoção imediata da gerência geral devido à "ineficiência grosseira, má gestão, falta de iniciativa e [...] promover frustração e apatia geral entre os trabalhadores."73

Em um caso semelhante, o WDC da subsidiária da UAC Ghana Textile Printing (GTP) assumiu a gestão da fábrica e a UAC perdeu todo o controle. A assunção veio após um período difícil para a fábrica, que tivera grandes perdas desde 1978 devido à falta de tecido produzido localmente para estamparia, e a falta de divisas significava que produtos químicos essenciais e corantes não poderiam ser importados. Em 1982, a UAC acordou uma demissão em massa do seu pessoal com o sindicato e o governo do PNDC, o que teria levado centenas de trabalhadores da GTP a perder seus empregos. No entanto, antes que as demissões entrassem em vigor, o GDC/WDC assumiu a fábrica. Contrariando seu acordo anterior com a empresa, o governo decidiu apoiar os trabalhadores organizados no WDC, dizendo que "eles agora devem demonstrar que podem ter sucesso". ${ }^{74}$ Embora a tomada de controle tenha ocorrido em novembro de 1982, somente no mês de janeiro seguinte a administração sênior da UAC entendeu completamente o que havia acontecido com sua fábrica e que havia realmente perdido o controle. ${ }^{75}$

\section{Restabelecimento do direito de gestão da administração}

Em 1987, o governo do Gana convidou a UAC/Unilever e seu parceiro técnico Vlisco a retomar a fábrica GTP. Embora os trabalhadores tivessem mantido a planta em um estado bastante bom de manutenção desde o controle da fábrica pelo WDC, muito pouco tecido estava sendo produzido e o negócio apresentava elevadas perdas. Nos anos que se seguiram à tomada do controle, a produção da fábrica tinha diminuído para 1,5 milhão de metros, de 2,5 milhões de metros no momento da tomada de posse (já abaixo de 17,5 milhões de metros em 1976), mantendo a sua força de trabalho total de 1.100 empregados. O plano de reestruturação da UAC para a fábrica incluiu a demissão de mais de 500 pessoas e, ao mesmo tempo, o emprego de gerentes expatriados. Como já esperado, dados os detalhes da proposta, a força de trabalho permaneceu hostil ao retorno do controle da fábrica pela UAC. ${ }^{76}$ Dessa vez, porém, o governo de Rawlings apoiou o plano da UAC e dominou os trabalhadores.

O retorno do GTP fazia parte de um processo mais amplo de reformas neoliberais e de despolitização do local de trabalho, que havia começado em abril

\footnotetext{
UGA HRD BOX148 Minutes of Workers Defence Committee, GCMT Division, Nsawam, 7 fev. 1983.

2 UGA HRD BOX148 Minutes of Workers Defence Committee, GCMT Division, Nsawam, 7 fev. 1983.

3 UGA HRD BOX154 J. E. K. Moses, Industrial Relations Report, Ghana para março/abril de 1982.

4 UARM UAC/2/12/2/1/5/4 UAC Textiles Visit Report B. J. Dale, on visit to Ghana, 4-6 dez. 1982.

5 UARM UAC/1/1/1/2/41 UACI Minute Book 38, p. 11 (Minutes of Board Meeting $1 \mathrm{fev} .1983$ ).

6 UARM UAC/2/12/2/1/5/4 C. E. Nichols, Proposal Ghana Textile Printing Company Limited (6 maio 1987).
} 
de $1983 .{ }^{77}$ Durante décadas, os governos de Gana haviam reivindicado o controle efetivo do emprego formal, incluindo: a hierarquia dos sindicatos; salários pagos em todos os setores da economia; o emprego de expatriados; e a realização de demissões. O Estado também controlava aspectos-chave da economia em geral, incluindo: a importação de bens e serviços; os preços dos produtos agrícolas e muitos outros itens; a taxa de câmbio da moeda cedi e a capacidade de aquisição de divisas; a propriedade de empresas (incluindo as estatais); e a capacidade das empresas estrangeiras repatriarem lucros. Os sucessivos governos que tentaram conter o declínio econômico de Gana diferiram em seu estilo e visão ideológica, mas todos implementaram medidas que aumentaram o controle do governo e que tornaram a economia de Gana cada vez mais fechada. Muitas dessas especificidades da economia ganense foram desmanteladas pelo autoproclamado governo revolucionário de Rawlings, que em seus primeiros estágios havia adotado uma forte mensagem anti-imperialista. Em abril de 1983, adotou um programa de estabilização econômica, apoiado pelo $\mathrm{FMI}$, que foi o primeiro de uma série de políticas de ajustamento estrutural, que ao longo dos anos eliminou grande parte do controle estatal; liberou os preços e aumentou os salários; cortou despesas públicas; desvalorizou a moeda; liberou a importação e a exportação; atraiu investimentos e ajuda estrangeiros; e, globalmente, buscou tornar a economia ganense muito mais aberta e competitiva. ${ }^{78}$

Até que ponto essas reformas neoliberais alcançaram seus declarados objetivos de estabilizar a economia, reduzir a pobreza e permitir o crescimento econômico, continua sendo um tema de debate. ${ }^{79}$

Os benefícios das reformas para a UAC foram bastante modestos. Os anos de 1984 e 1985 viram lucros em algumas partes do negócio que se beneficiaram da crescente disponibilidade de bens, como o comércio geral e as lojas de departamentos, enquanto os negócios permaneceram difíceis para as empresas de produção. A partir de 1986, as perdas começaram a crescer e outras partes do negócio foram fechadas - como (em 1989) a icônica loja de departamento Kingsway - , ou vendidas. ${ }^{80}$

A presente discussão limita-se ao impacto das reformas no ambiente de trabalho, em particular às relações entre a gestão da empresa e a mão de obra organizada. A posição desta última foi enfraquecida pelas severas perdas de postos de trabalho. Isso não foi exclusividade da UAC. Empresas estatais e privadas em toda a economia eliminaram centenas de milhares de empregos, resultando em uma queda na filiação sindical e um correspondente enfraquecimento do poder de barganha do trabalho organizado. Ao mesmo tempo, o governo eliminou leis trabalhistas e convenções coletivas que protegiam os direitos dos trabalhadores. ${ }^{81}$

Os primeiros anos do regime do PNDC proporcionaram muitas oportunidades de participação dos trabalhadores na organização do ambiente de trabalho, embora houvesse também muitas tensões e lutas entre os sindicatos, os conselhos de defesa dos trabalhadores, a administração da empresa e o Estado. A partir de

77 RIMMER. Staying Poor, p. 183.

78 RIMMER. Staying Poor, p. 183-192; LOXLEY, John. "Structural Adjustment in Africa: Reflections on Ghana and Zambia". Review of African Political Economy, v. 47, p. 8-27, 1990.

79 KONADU-AGYEMAN, Kwadwo (org.). IMF and World Bank Sponsored Structural Adjustment Programs in Africa: Ghana's Experience, 1983-1999. Aldershot: Ashgate, 2001; HILSON, Gavin "Structural adjustment in Ghana: Assessing the impacts of mining-sector reform". Africa Today, v. 51, n. 2, p. 53-77, 2004; KRAUS, Jon. "The struggle over structural adjustment in Ghana". Africa Today, v. 38, n. 4, p. 19-37, 1991.

80 UARM UAC/1/1/1/2 Board Minutes Series para 1980 s.

81 KONINGS. "Structural adjustment and trade unions", p. 320-321. 
1984, isso mudou decisivamente: o governo do PNDC continuou a lutar contra o movimento sindical "egoísta", ao mesmo tempo em que abolia os Comitês de Defesa dos Trabalhadores, deixando-os menos protegidos e com menos oportunidades de participar no funcionamento dos seus ambientes de trabalho. Muitos empregadores exploraram a posição enfraquecida dos seus trabalhadores para introduzir contratos de trabalho mais flexíveis, recrutar trabalhadores ocasionais, introduzir novas e mais rigorosas regras e, em geral, reduzir a segurança no emprego. ${ }^{82}$

Esse aumento da flexibilidade gerencial restabeleceu o "direito da administração de gerir" a níveis vistos pela última vez no início dos anos 1950. No entanto, a gestão local de uma empresa ainda (relativamente) grande e de longa data como a UAC não estava preparada para tal situação. Depois de anos de prolongado controle estatal, de um contexto macroeconômico deficiente, de recursos limitados e, consequentemente, de baixo investimento no negócio (inclusive no desenvolvimento de pessoal), muitos de seus gerentes simplesmente não estavam preparados para o ambiente empresarial em mudança. Isso explica a insistência da empresa em trazer mais gerentes expatriados, e também a integração mais próxima das atividades restantes em Gana com sua organização empresarial internacional. Em 1987, o tamanho das operações da UAC em Gana tinha sido significativamente reduzido em comparação com as décadas de 1950 e 1960, e a empresa já não era tão dominante na economia do país como tinha sido no momento da independência. $O$ número de trabalhadores por ela empregados havia sido adequadamente reduzido. A intervenção direta do Estado tinha sido muito reduzida e os já fracos sindicatos foram enfraquecidos ainda mais. Os Comitês Revolucionários de Defesa dos Trabalhadores já não existiam e haviam sido substituídos por um retorno à estrutura anterior dos Comitês Consultivos Conjuntos, em que a administração se reunia com os funcionários para apresentar planos e discutir queixas gerais.

\section{Conclusão}

A greve geral de janeiro de 1950 teve lugar durante um período da história ganense que viu greves maiores e menores, um movimento operário em ascensão, uma situação política instável devido à luta nacionalista contra o governo colonial, uma administração cuja legitimidade era contestada e considerável liberdade para os executivos das empresas tomarem suas próprias decisões sobre recrutamento, salários e condições de trabalho. Isso teve o potencial de politizar e desestabilizar as condições no ambiente de trabalho, particularmente numa companhia como a UAC, que era percebida como dominando a economia e intimamente associada ao poder colonial. Tanto a administração da UAC como a liderança do sindicato "da casa", o Sindicato dos Empregados Africanos da UAC, temiam as consequências da politização do ambiente de trabalho no contexto da luta nacionalista e tentaram assegurar que isto não acontecesse. Contudo, tendo Nkrumah subido ao poder não puderam evitar serem incluídos na reestruturação da economia formal e do movimento dos trabalhadores que apoiavam a visão de desenvolvimento político e econômico para o país independente. Não só isso. Durante a década de 1950 a UAC era tão grande e tão visível como uma companhia estrangeira intimamente ligada

82 KONINGS. "Structural adjustment and trade unions", p. 320-321. 
ao imperialismo que isso foi alcançado de maneira muito pública e conflituosa, o que resultou em severas tensões no ambiente de trabalho da UAC.

Em torno de 1987, o ambiente de trabalho da UAC havia se transformado consideravelmente. A UAC desempenhava um papel muito menos dominante na economia ganense e a UAC de Gana era agora uma companhia localmente registrada, embora a Unilever continuasse a deter $40 \%$ das ações e a controlar o negócio por meio dos seus executivos seniores. Depois de décadas, durante as quais o espaço de negociações entre sindicatos e administração havia sido limitado pela extensa regulamentação governamental das relações de trabalho e da economia, o ambiente de trabalho teve de se haver com uma situação em que o Estado tinha mudado radicalmente sua perspectiva face às relações de trabalho. A empresa repeliu a legislação que pretendia proteger os direitos e segurança do emprego, salários e preços das necessidades cotidianas, ao mesmo tempo em que minava a posição dos sindicatos e sua habilidade para negociar em favor de seus membros. A administração viu, assim, restaurado seu "direito de dirigir", mas a maioria dos executivos médios foram insuficientemente treinados e experimentados para prover liderança efetiva nas novas circunstâncias. Para os empregados da UAC, isso significava que os anos 1980 foram um período de insegurança do emprego e frequente reorganização, prejudicados por obstáculos para se organizarem e se engajarem num diálogo construtivo com a direção da empresa. Por volta de 1992, a maior parte da antes dominante companhia tinha sido fechada e vendida para outras companhias, e as atividades remanescentes foram integradas a um empreendimento muito menor, a Unilever Gana, que empregava muito menos trabalhadores do que a UAC havia empregado.

Da década de 1950 ao início da de 1980, o controle estatal das relações de trabalho reduziu o espaço de negociação entre sindicatos e empresa. Embora os executivos seniores da UAC considerassem a estrutura centralizada dos sindicatos de Gana inteiramente insatisfatória (particularmente comparada com a situação da Nigéria, onde tal nível de controle não existia), esse arranjo não impediu o ambiente de trabalho de se politizar. ${ }^{83} \mathrm{Na}$ verdade, enquanto a incapacidade dos reduzidos aumentos salariais de acompanhar o aumento do custo de vida fosse uma fonte de tensões e greves, outra causa frequente de protesto e ações grevistas não oficiais seria o alegado tratamento racista e injusto do pessoal africano pelos gerentes europeus. Isso advinha, em parte, de queixas genuínas e em parte refletia um discurso político consistente que enfatizava o anti-imperialismo e as tendências exploradoras das companhias estrangeiras. Como a liderança nacional do TUC tinha que colaborar de perto com os sucessivos governos ganenses, o protesto no ambiente de trabalho era frequentemente informal. Esse conjunto de arranjos eventualmente terminou durante a fase revolucionária do governo do PNCD que logo se dispôs a minar a estrutura do TUC e a encorajar a participação direta do trabalhador na gerência por meio dos Comitês de Defesa dos Trabalhadores (Workers' and People's Defence Committees), terminando por aboli-los em 1984 e a desmantelar a maior parte da legislação trabalhista, que até então regulava as relações entre trabalhadores e a direção das empresas e que vinha protegendo os interesses dos trabalhadores em alguns aspectos.

Durante a maior parte desse período, apesar de sua aparência de fraqueza, da economia declinante, golpes militares e desafios frequentes à sua legitimidade, o Estado ganense se manteve extremamente influente e eficiente, e a UAC 
respondeu a todas as demandas, mesmo quando às vezes a gerência local da UAC ficasse furiosa com tais demandas e a mesa diretora da UAC em Londres fosse levada ao desespero. Em geral, os arranjos seriam uma faca de dois gumes para o trabalhador da UAC. Eles conseguiram estabilidade nas relações de trabalho, mas ao custo de salários relativamente baixos e uma economia declinante, o que no final impedia investimentos em equipamentos e o desenvolvimento dos empregados. O rápido e, para a UAC, inesperado colapso do sistema desestabilizou o ambiente de trabalho. Os trabalhadores temiam perder seus empregos e os gerentes da UAC não puderam usar seu "direito ao mando" recentemente restaurado para prover uma liderança efetiva (terá aumentado o problema o colapso econômico da vizinha Nigéria, onde a UAC tinha operações muito maiores - e até recentemente, muito mais lucrativas).

A rápida implementação de reformas neoliberais, depois de abril de 1983, também chama nossa atenção para a extensão com que esse ambiente de trabalho em particular foi influenciado por tendências econômicas e políticas globais mais amplas. Em muitos aspectos, o desenvolvimento do ambiente de trabalho ganense foi semelhante àquele da antiga potência colonial, o Reino Unido, onde, mais ou menos na mesma época, o governo de Margaret Thatcher também restaurou "o direito da gerência de gerir" com um conjunto consistente e violento de confrontos com os sindicatos britânicos. ${ }^{84}$ 
